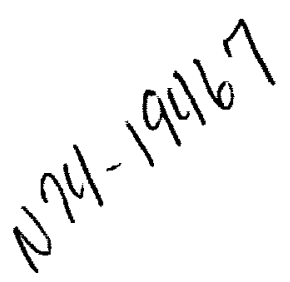

\title{
31. On the Manganese Content of Cosmic Flakes From Deep-Sea Sediments
}

\author{
KARL UTECH \\ Gesellschaft für Weltraumforschung \\ Bonn-Bad Godesberg, West Germany
}

\begin{abstract}
Cosmic flakes belong to the category of cosmic microparticles. They occur together with cosmic spherules in sediments (Utech, 1965). These flakes appear to represent ablation products of iron meteorites burnt away during the passage of a meteorite through the almosphere by friction against air molecules. Microprobe analyses of flakes from deep-sea deposits proved the particles to consist of magnetite which in most cases had been altered into maghemite in the outer zones. This is in agreement with the assumption that they represent fragments of fusion crust of iron meteorites. Most of the flakes, however, contained a small percentage of manganese. This element is not a common constituent of iron meteorites. The author attempts to explain the presence of manganese in fakes and its absence in cosmic spherules.
\end{abstract}

$\mathrm{M}$ AGNETITE FLAKES of decp-sea sediments were known to most investigators for a long time but little attention was paid to these particles until a relationship was found to exist in the frequency of the occurrence between flakes and cosmic spherules on occasion of an investigation of Permian rock salt, sampled from a pit in the vicinity of Wolfenbüttel, northern Germany.

Rock salt is formed in shallow basins which have become cut off from the open occan. Thus the water is allowed to evaporate and salt is precipitated. The rate of salt formation is high and consequently the concentration of cosmic spherules therein contained is low. During the work on the rock salt samples it was noticed that the concentration of flakes was also low in contrast to deep-sca deposits where spherules and flakes are plentiful. This was the first hint that the flakes might be of cosmic origin.

As judged by their magnetic properties and confirmed by microprobe and Debye-Scherrer analyses, the flakes consist of magnetite. Most of those extracted from decp-sea sediment cores were weathered and more highly oxidized in the outer zones to maghemite. Microprobe analyses showed however the flakes from decp-sea sediments containcd some manganese of the order of magnitude from 0.5 to 2.0 percent. Manganese is not a common constituent of iron meteorites of which the flakes were assumed to be ablation products, but is present in deep-sea deposits.

A check on cosmic spherules from the same sedimonts confirmed previous analyses that spherules did not contain manganese, at least not in their internal parts. Now the question arose if the flakes could be of cosmic origin and be ablation products of iron meteorites as the spherules are, if they contained manganese and the spherules did not. To solve this question the following investigations were carried out.

Thin sections of flakes were studied under high magnification. They showed the same magnetite skeletons as cosmic spherules. Apparently during their genesis they must have been in a \pm liquid 
state and then rapidly chilled, as cosmic spherules too. However the mechanics of origin of flakes appear to differ from those of spherules. Flakes, or fusion crust respectively, are practically burnt off a meteorite whereas spherules are detached from the surface of fusion crust. Some flakes showed a certain flow structure at the surface as sometimes can also be observed on fusion crust of iron meteorites. One flake was found with an almost perfectly developed spherule at its surface. Apparently this flake was torn from the meteorite prior to the detachment of the spherule from the fusion crust. These observations are in agreement with the assumption that the flakes are of cosmic origin.

In order to find out how manganese could penetrate the flakes and not the spherules, some flakes from deep-sea deposits were cut into two pieces and embedded upside down for analyses with the microprobe analyzer. Then the electron beam was moved slowly across the flake to determine whether the mangancse contents varied within an individual flake. This assumption could however not definitely be proved, although several of thesc analyses had been carried out.

The same test was repeated on a flake from a rock-salt sample. It did not contain manganese and consisted of high-grade magnetite only.

As previously mentioned, rock salt is formed in shallow basins which have become separated from the open sea. In contrast to deep-sea deposits, shallow waters do not contain manganese in any appreciable amount. As a consequence, flakes which fell into these basins cannot be contaminated with manganese as seems to be the case with those which fell into the deep ocean and became embedded in sediments containing this element.
Flakes which in most cases are only a few microns thick are exposed with all sides to the manganese of the sediment, thus offering this element the possibility to penetrate the flakes from all directions in the course of time.

Cosmic spherules, on the other hand, offer the manganese only their external sides. Furthermore, the shclls of the spherules are often thicker than the flakes. For these reasons manganese is prevented from penetrating spherule magnetite thoroughly. The flakes and spherules worked with had been extracted from deep-sea sediments of Quaternary age. Perhaps spherules embedded in older deep-sea sediments may also contain some manganese as the time factor cannot be overlooked in the process of manganese penetration, but this is an unproved assumption as such sediments had not been available.

\section{CONCLUSIONS}

Flakes and spherules are of the same composition when extracted from sediments which do not contain manganese. If manganese is present in the sediment, it penetrates the thin flakes in the course of time. This penetration takes place from all sides of the flakes, in contrast to cosmic spherules which offer the manganese only their external sides. As the shells of spherules are also thicker than flakes, manganese cannot penetrate the magnetite of spherules thoroughly, but may only be detected at the surface of uncleaned species.

These conclusions should not be extended at the present time to cosmic spherules embedded in deep-sea sediments of an age older than Quaternary.

\section{REFERENCE}

Utech, KarL, 1965. Kosmische Magnetitflitter in Sedimenten, N. Jb. Geol. Paläont. Mh. 3, 164-166. 